\title{
Late diagnosis of leukocyte adhesion deficiency type II and Bombay blood type in a child: a rare case report
}

\author{
YÖNTEM YAMAN ${ }^{1}$, SULTAN AYDIN KÖKER ${ }^{2}$, FAHRI YÜCE AYHAN ${ }^{3}$, FERAH GENEL ${ }^{4}$, \\ CAN ACIPAYAM ${ }^{5}$, YEŞIM OYMAK ${ }^{2}$ EBRU TUĞRUL SARIBEYOĞLU ${ }^{1}$, CANAN RAZIYE VERGIN ${ }^{2}$ \\ 'Division of Paediatric Haematology, Medipol University Hospital, Istanbul, Turkey \\ ${ }^{2}$ Division of Paediatric Haematology, Dr. Behçet Uz Children's Hospital, Izmir, Turkey \\ ${ }^{3}$ Division of Microbiology and Clinical Microbiology, Dr. Behçet Uz Children's Hospital, Izmir, Turkey \\ ${ }^{4}$ Division of Paediatric Immunology, Dr. Behçet Uz Children's Hospital, Izmir, Turkey \\ ${ }^{5}$ Division of Paediatric Haematology, Kahramanmaraş Sütçü Imam University, Kahramanmaraş, Turkey
}

\begin{abstract}
Leukocyte adhesion deficiency type II (LAD II) is a rare, autosomal, recessive inherited immunodeficiency disease that induces frequent and recurrent infections, persistent leukocytosis, severe mental and growth retardation, and impaired wound healing. The Bombay blood group is a rare blood group phenotype that is characterised by the deficiency of $H, A$, and $B$ antigens on the surface of red cells. LAD II and the Bombay blood group are always seen together, because both of them are associated with a global defect in the common pathway of fucose metabolism. Here we report the case of an 11-year-old boy with LAD II, who presented with the Bombay blood group. Agglutination with strength of 4+ was detected in all cross-matching due to erythrocyte transfusions for our patient. Therefore, the Bombay blood group was incidentally determined due to deficient expression of the CD15 adhesion molecules on the surface of the leukocytes according to the results of flow cytometry. Upon detecting the Bombay blood type, LAD II was then diagnosed as a result of flow cytometry and the clinical findings of mental retardation and history of recurrent infections such as abscesses.
\end{abstract}

Key words: leukocyte adhesion deficiency type II, Bombay blood group.

(Centr Eur J Immunol 2019; 44 (2): 206-209)

\section{Introduction}

Leukocyte adhesion deficiency (LAD) was first reported in the 1980s [1]. LAD is an autosomal recessive disorder and a rare congenital immunodeficiency that has been classified into three types: LAD I, II, and III [2]. LAD II is the rarest of the three types, and it has been reported in fewer than 10 patients [3]. LAD II is characterised by recurrent severe bacterial infections, the absence of pus formation, periodontitis, delayed wound healing, often persistent leukocytosis, and severe mental and growth retardation [2, 4].

The Bombay blood group was first described in 1952 [5]. Based on the genetic defect, it is characterised serologically by the absence of $\mathrm{H}, \mathrm{A}$, and $\mathrm{B}$ antigens on the surface of red cells as well as the presence of corresponding antibodies in the serum. It is present in blood group O [5]. In the general population, the prevalence of the Bombay blood group is about 1 in 10,000 individuals in India and 1 in 1,000,000 individuals in Europe [6]. The incidence of the Bombay phenotype blood group was reported to be around $0.01 \%$ in recent studies [7].
While loss of function of Golgi guanosine diphosphate (GDP)-fucose transporter 1 results in impaired leukocyte migration in LAD II, defective mutations of fucosyltransferase enzymes, encoded by two different genes known as FUT 1 (H gene) and FUT 2 (Se gene), give rise to the Bombay blood phenotype [8-10]. Because both the Bombay blood group and LAD II can be detected as global defects in fucose metabolism, they are seen together [11].

We report a rare case of an individual having both LAD II and the Bombay blood group, a condition that was mistyped as the $\mathrm{O}$ group.

\section{Case report}

An 11-year-old boy was referred to the haematology department because of chronic diarrhoea. He was born full-term to healthy first-degree consanguineous parents with a birth weight of $1250 \mathrm{~g}$ (below the third percentile). According to his medical history, he had been hospitalised due to intrauterine growth retardation during the first three

Correspondence: Sultan Aydin Köker, Division of Paediatric Haematology and Oncology, Dr. Behçet Uz Children's Hospital, Izmir, Turkey, e-mail: drsultanaydin@hotmail.com

Submitted: 10.10.2017; Accepted: 2.02.2018 
weeks of his life. As an infant he suffered from delayed separation of the umbilical cord. He developed multiple recurrent infections such as pneumonia, diarrhoea, fever, and recurring skin abscesses. On physical examination, his height and weight were both found to be below the third percentile. He had dysmorphic features such as a coarse facial appearance, flattened nose, and long prominent philtrum. He had numerous scars from abscesses in the bilateral inguinal region. A neurological examination revealed that he had severe growth and psychomotor retardation (Fig. 1). He had $2 \mathrm{~cm}$ of hepatomegaly and $4 \mathrm{~cm}$ of splenomegaly. A laboratory evaluation at the age of 11 years revealed that he had an elevated white blood cell count $\left(72.1 \times 10^{9} / 1\right)$ with neutrophilia $(80 \%$ neutrophils, $20 \%$ lymphocytes). His haemoglobin level was $9 \mathrm{~g} / \mathrm{dl}$, mean corpuscular volume was $76 \mathrm{fl}$, and platelet level was $456 \times 10^{9} / 1$. The other blood parameters were normal.

He had no history of blood transfusions. On the $10^{\text {th }}$ day of follow-up, an erythrocyte transfusion was required because his haemoglobin level had decreased. His blood group was typed as $\mathrm{O}$ Rh D positive using the gel centrifugation method for $\mathrm{ABO}$ and Rh typing (Fig. 2A). A transfusion of one unit of packed red blood cells was planned, but severe haemolytic reactions developed during a crossmatch related to all of the erythrocyte suspensions.

The presence of Lea, Leb, and $\mathrm{H}$ antigens in the erythrocytes of the patient was investigated using haemagglutination tests performed with commercial monoclonal antiserums (ALBAclone, Alba Bioscience, United Kingdom) derived from mice. At the same hospital, his blood grouping was again reported as $\mathrm{O} R \mathrm{R} \mathrm{D}$ positive by $\mathrm{ABO}$ and $\mathrm{Rh}$ typing on the gel card. The forward and reverse grouping on the tube revealed the blood group to be $\mathrm{O} \mathrm{Rh} \mathrm{D}$ positive. It was found to be incompatible with a strength of 4+ agglutination in all cross-matches using reverse analysis conducted with erythrocytes from A1, A2, B, and O blood groups. Reaction with anti-H lectin was negative. The blood group was finally
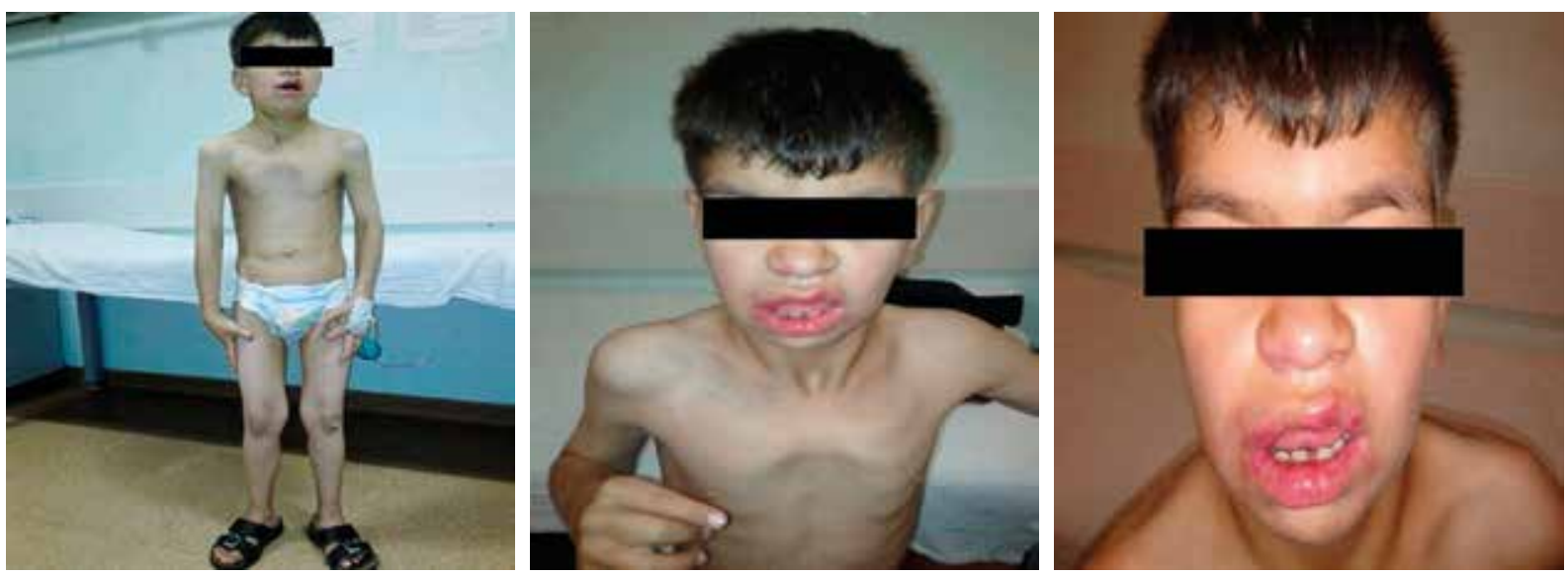

Fig. 1. Facial appearance of the patient
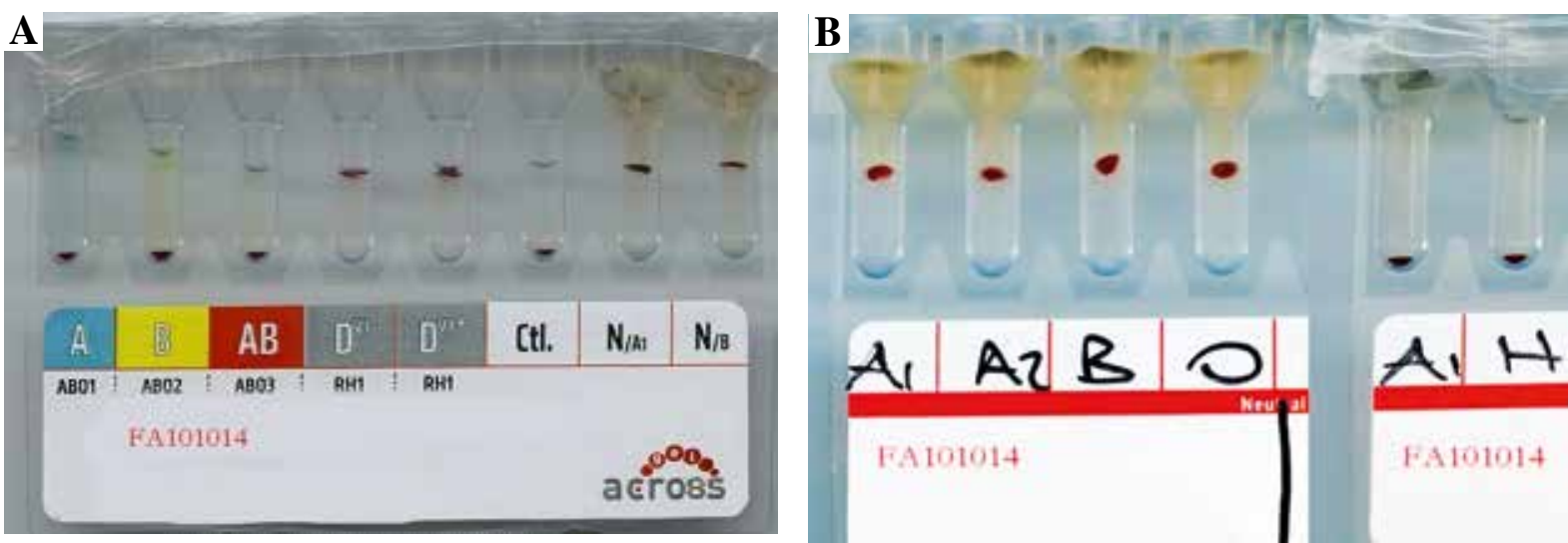

Fig. 2. A) ABO and Rh blood group typing. B) Agglutination with strength of 4+ in all cross-matching with erythrocytes of $\mathrm{A} 1, \mathrm{~A} 2, \mathrm{~B}$, and $\mathrm{O}$ blood group and anti-H lectin was negative 

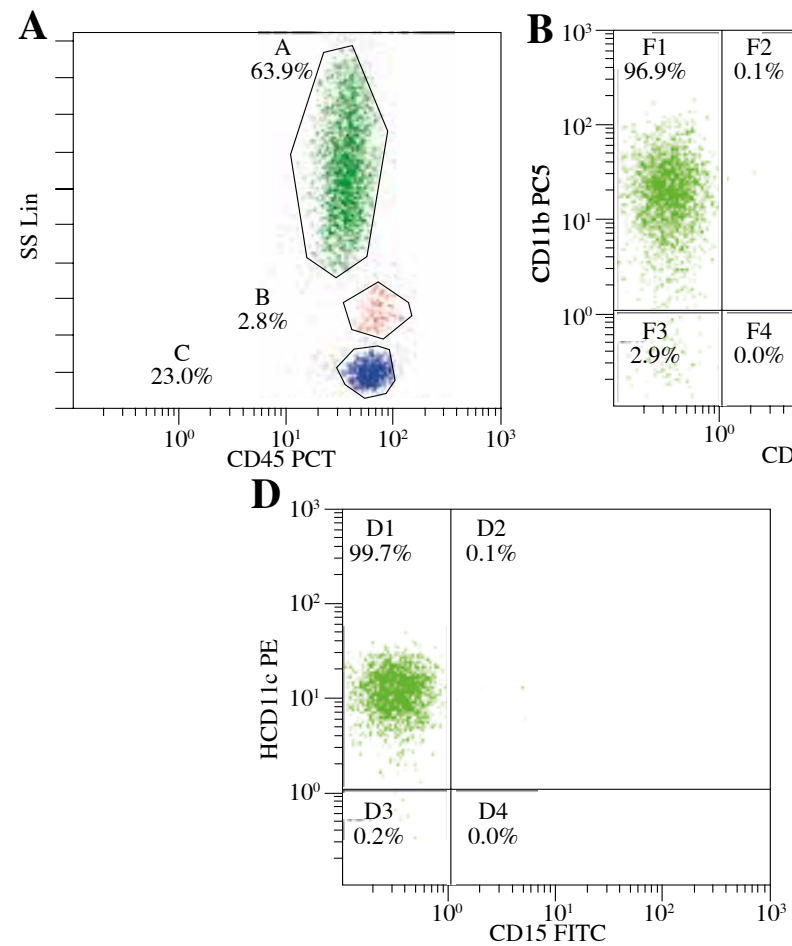
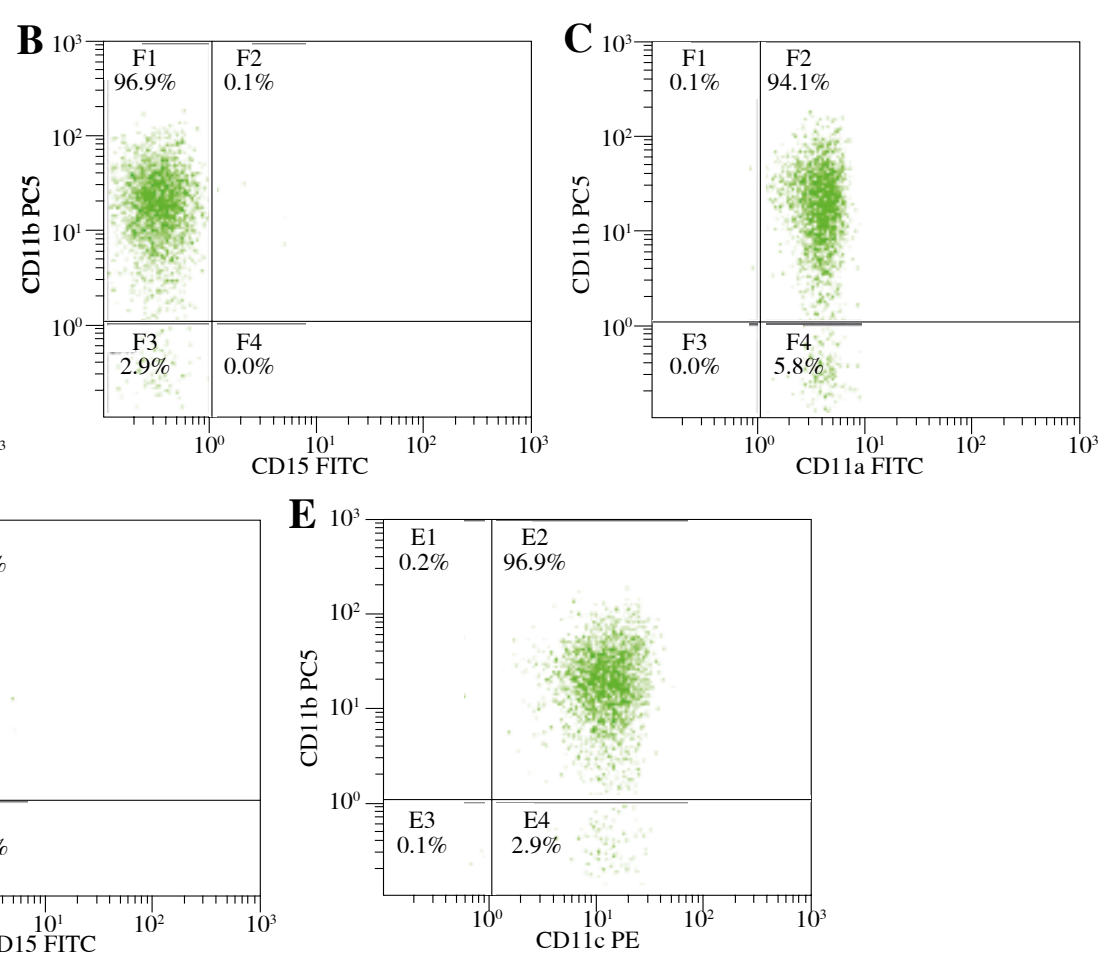

Fig. 3. Expression of CD11a, 11b, 11c, and CD15 by flow cytometry

interpreted as the Bombay blood group with naturally occurring anti-H antibodies in the plasma (Fig. 2B).

The molecular basis of LAD II was demonstrated to be the deficient expression of the CD15 adhesion molecules on the surface of the leukocytes. The expression of LFA-1 (CD11a/CD18), Mac-1 (CD11b/CD18), and p150/95 (CD11c/CD18) was not absent (Fig. 3). CD18 expression could not be determined due to the lack of a CD18 kit.

Because the patient's haemoglobin level was not low enough for erythrocyte transfusion, we started iron therapy. The patient's haemoglobin level then elevated, so he did not require the transfusion.

We considered this to be a case of an individual having both LAD II and the Bombay blood type, based upon the present findings. However, our patient did not return to our hospital for follow-up after this diagnosis of LAD II and the Bombay blood type. Instead, he returned to his home province (Kahramanmaraş). Thus, we could not perform molecular genetic analysis on our patient.

\section{Discussion}

The Bombay blood group occurs due to the point mutation of the $\mathrm{H}$ gene. It results in a lack of production of the protein fucosyltransferase, which is coded by the $\mathrm{H}$ gene. Thus, in patients with the Bombay blood group, the $\mathrm{H}$ antigen cannot be produced due to the absence of this protein. Normally, A and B gene specified products cause an addition of $\mathrm{N}$-acetyl galactosamine and $\mathrm{D}$-galactose to the $\mathrm{H}$ antigen to form $\mathrm{A}$ and $\mathrm{B}$ antigens, respectively. In the absence of the $\mathrm{H}$ antigen, these reactions cannot take place. Thus, the A and $\mathrm{B}$ antigens are not produced even if the $A$ and $B$ genes are present. People who lack the $\mathrm{A}, \mathrm{B}$, and $\mathrm{H}$ antigens in their blood produce anti-A, anti-B, and anti-H antibodies as a consequence. The absence of $\mathrm{A}$ and $\mathrm{B}$ antigens mimics the $\mathrm{O}$ blood group, but the presence of the anti-H antibody causes a cross-reaction with all blood types, including the $\mathrm{O}$ group blood, which carries the $\mathrm{H}$ antigen [12]. Despite its rarity, the clinical significance of this condition must not be underestimated due to its role in causing transfusion reactions [13]. In our case study, the $\mathrm{O}$ blood group was identified with both forward and reverse grouping in the $\mathrm{ABO}$ typing, but a cross-reaction with all blood types, including the O blood group, was detected in our patient. Upon difficulty in getting a suitable cross-matched blood unit, the patient's blood was screened for the Bombay blood group. The presence of the anti-H antibody was detected while testing using anti-H antisera.

Patients with LAD II also suffer from recurrent infections, growth retardation, developmental delay, and dysmorphic features $[2,4]$. The leukocyte adhesion defect in the LAD II syndrome is best understood in the context of our current knowledge of leukocyte adhesion and trafficking processes. LAD II neutrophils are deficient in the expression of P-, E-, and L-selectin ligand activity, and they exhibit a correspondingly diminished ability to adhere 
to the endothelium and to migrate to inflammatory sites in vivo $[14,15]$. Therefore, an early complete deficiency of Sialyl-Lewis X (SLex) expression (CD15) can be determined in LAD II neutrophils by using flow cytometry analyses [11]. Our patient had typical features of LAD II, such as recurrent infections, absence of pus formation, persistent leukocytosis, severe mental and growth retardation, and delayed wound healing. At the same time, he had normal expression of CD11a, CD11b, and CD11c but no expression of CD15. CD18 expression could not be determined due to the lack of a CD18 kit using flow cytometry. Thus, we concluded that our patient had LAD II.

Consequently, if recurrent infections, persistent hyperleukocytosis, and severe mental and growth retardation are present in an individual with the Bombay blood group, we should consider the possibility of the rare diagnosis of LAD II. Genetic counselling is required for these patients.

The authors declare no conflict of interest.

\section{References}

1. Curnutte JT, Crowley CA, Rosin RE, et al. (1980): Defective neutrophil adhesion due to an inherited deficiency of a specific glycoprotein. Trans Assoc Am Physicians 93: 85-93.

2. Etzioni A, Doerschuk CM, Harlan JM (1999): Of man and mouse: leukocyte and endothelial adhesion molecule deficiencies. Blood 94: 3281-3288.

3. Dauber A, Ercan A, Lee J, et al. (2014): Congenital disorder of fucosylation type 2c (LADII) presenting with short stature and developmental delay with minimal adhesion defect. Hum Mol Genet 23: 2880-2887.

4. Gazit Y, Mory A, Etziona A, et al. (2010): Leukocyte adhesion deficiency type II: long-term follow-up and review of the literature. J Clin Immunol 30: 308-313.

5. Bhende YM, Deshpande CK, Bhatia HM, et al. (1952): A new blood group character related to the ABO system. Lancet 1: 903-904.

6. Oriol R, Canelier JJ, Mollicone R (2000): Molecular genetics of H. Vox Sang 78: 105-108.

7. Dipta TF, Hossain AZ (2011): The Bombay blood group: are we out of risk? Mymensingh Med J 20: 536-540.

8. Lubke T, Marquardt T, Etzioni A, et al. (2001): Complementation cloning identifies CDG-IIc, a new type of congenital disordersof glycosylation, as a GDP-fucose transporter deficiency. Nat Genet 28: 73-76.

9. Hirschberg CB (2001): Golgi nucleotide sugar transport and leukocyte adhesion deficiency II. J Clin Invest 108: 3-6.

10. Shechter Y, Etzioni A, Levene C, et al. (1995): A Bombay individual lacking $\mathrm{H}$ and Le antigens but expressing normal levels of K-2- and K-4-fucosyl transferases. Transfusion 35: 773-776.

11. Etzioni A, Frydman M, Pollack S, et al. (1992): Recurrent severe infections caused by a novel leukocyte adhesion deficiency. N Engl J Med 327: 1789-1792.

12. http://www.austincc.edu/kotrla/bblec6ABOSPG05 (access: 2014 Sep 18).
13. Schricker KT, Neidhardt B, Hacker R, et al. (1983): Heart surgery in a female patient with blood group Oh (Bombay phenotype). Dtsch Med Wochenschr 108: 61-63.

14. Springer TA (1994): Traffic signals for lymphocyte recirculation and leukocyte emigration: the multistep paradigm. Cell 76: 301-314.

15. Kansas GS (1996): Selectins and their ligands: current concepts and controversies. Blood 88: 3259-3287. 